
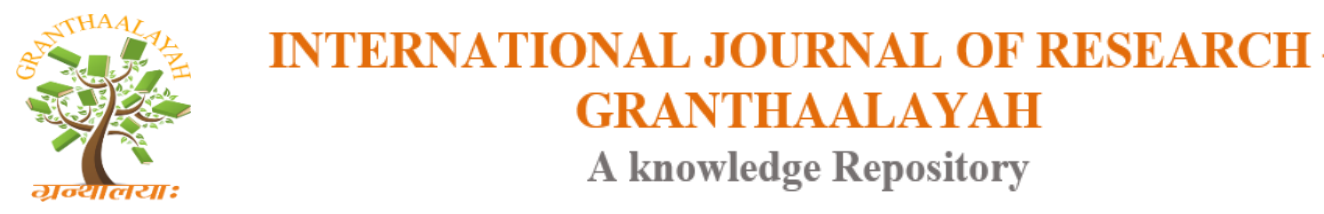

Social

\title{
STUDY ON LOCUS OF CONTROL CONTRIBUTING TO SUPERSTITIOUS BEHAVIOR
}

\author{
Dr. Manasvi Shrivastav *1 \\ ${ }^{* 1}$ Department of Psychology, Dev Sanskriti Vishwavidyalaya, Haridwar(UK), India
}

\begin{abstract}
The purpose of the study is to assess the relationship between locus of control and superstitious behavior of people of UP. 300 participants were selected through quota sampling from various places of UP. Age and education related factors treated as controlled variables. To assess locus of control in subjects Hindi adaptation of "Rotter's Locus of Control scale" of Dr. Anand Kumar \& S.N. Srivastav has been used. It consists of 29 items in it. Superstitious Behavior Scale (selfconstructed) has been used, which is consisting of 40 items. Each item have three alternatives: (a) I will definitely do it. (b) If not possible, I will not do it. (c) I don't believe in it. Ex-post facto research design has been used. Data is analyse by chi-square method. Result show that external locus of control is responsible for high superstitious behavior.
\end{abstract}

Keywords: Locus of Control; Superstitious Behavior; Rural Female; Rural Male; Urban Female; Urban Male.

Cite This Article: Dr. Manasvi Shrivastav. (2018). "STUDY ON LOCUS OF CONTROL CONTRIBUTING TO SUPERSTITIOUS BEHAVIOR." International Journal of Research - Granthaalayah, 6(5), 244-254. https://doi.org/10.29121/granthaalayah.v6.i5.2018.1446.

\section{Introduction}

...every man must judge for himself between conflicting vague probabilities.

- Charles Darwin, 1887

Superstition refers to the blind faith in an idea without giving any consideration to reason, logic and evidence. Many superstitions have originated in human society on account of ignorance and fear of unknown and incomprehensible. Many superstitions have disappeared in course of time as well. For instance, for many centuries lightening, hurricanes, floods, earthquakes and epidemics were assumed as the reflection of God's anger over the behaviour of human beings. To appease God, many rituals were carried out. Prayers were offered; fastings was undertaken and offerings were given to temples and even human sacrifices were made. These superstitions have vanished gradually during the last two centuries due to development and spread of scientific knowledge about nature and its manifestations. But still superstitious beliefs have been found in a diverse 
range of cultures and societies regardless of the level of technological development. Superstition persists today despite of people fundamentally not rely on mythical and irrational beliefs to explain and to control their environment. Most of the people follow different kind of superstitions. People of different age, different education, different socio-economic status and different culture, caste, creed etc. follow different superstitious rituals. Superstitions rooted deeply in our society despite of scientific knowledge and high education. Moreover, one may be superstitious regardless of one's socioeconomic or educational status. Although scientific researches and advancements change the scenario of our society, but some views of people doesn't change yet. People consistently believing in illogical believes and rituals in their life, which are known as superstition and termed as magical thinking by psychologists.

Some people believe in it for some task, but some other believes in external power or extra bit of luck, which could help to reach the aspired performance standard. Even though, by definition, luck is nothing else but chance, people go much further than simply hoping for good luck. In fact, many of them actually engage in certain kinds of thinking or behavior to gain that extra bit of good luck or prevent bad luck from happening.

In the literature, there are several definitions of superstition. Most authors agree on the fact that superstitions are beliefs or behaviors that are contrary to rational norms within a specific society. It implies that superstitious behaviors cannot be interpreted or explained according to religious beliefs which are usually not considered as irrational by members of a given society (Campbell, 1996). Superstitions are culturally anchored and differ according to countries. For example "Simmons and Schindler (2002)" demonstrate that, in China, prices ending with the digit 8 are very common because there is a local belief that number 8 brings luck, prosperity, and happiness. On the contrary, prices ending with digit 4 are under - represented because this number brings bad luck.

According to Devenport and Holloway, (1980), superstitious rituals are usually taking place in contexts of uncertainty. In a later article (Skinner, 1953), he suggested that seeing a causal relationship between behavior and the "consequences" also could explain the occurrence and maintenance of superstition in humans. A second, complementary explanation may be derived from Langer and colleagues' (Langer, 1975, 1977; Langer \&Roth, 1975) work on illusion of control. Langer stated that, in general, people are inclined to see themselves as a cause, even in situations in which they are not influencing the situation. This explanation holds that people carry out superstitious behaviours in order to influence situations in which, in reality, they have no control. According to Langer, this is especially true in situations in which chances as well as skill play a role. In competitive sports, there is always a mixture of chance as well as skill that determines the outcome of a match. Therefore, in these situations, people will probably be more prone to the illusion of control and superstition.

Sigmund Freud called such superstitions "faulty actions". Some psychologists consider them expressions of inner tensions and anxieties. Other believes intense superstitious feelings indicate some sort of mental disorder. However, there has been no reliable clinical correlation between superstitious beliefs and mental illness. 
People have a strong desire to understand cause and effect; such knowledge provides a degree of control over the future. At times, however, people infer causation between behaviour and outcomes when none actually exists. Depending on the literature read, such faulty inferences have been termed as illusion of control, superstitious thinking, or magical thinking.

When we look at the progression that normal mental development takes, as individuals mature, we see a gradual trend towards greater accuracy, as well as a greater dependency upon logical principles (Markovits \&vachon, 1989). However, there is one great mystery in our journey of cognitive development which violates an otherwise stable pattern of growth, and that is the advent and application of magical thinking. Magical thinking is a method of thinking, in which one believes that their thoughts words or actions will be able to influence reality in a way that fails to be supported by scientific evidence or causal reasoning. We typically see it employed in the form of superstitions and magical thinking.

Superstitious beliefs are prevalent in Indian culture. As a cat crossing the path, people stop walking for a while or changing the path. Sneezing before starting any work consider as the bad luck. With the superstitious belief talking about something may bring bad luck or good luck or some desirable consequences. Despite, superstitions are widely prevalent in India, to date, there is no such research examining the relationship of superstitions and socio-psychological variables. It would be interesting to study the relationship between superstitious behaviour and socio-psychological variables like stress level, Locus of control, self-confidence, gender and locale. This study thus aims to fill in the knowledge gap by examining if superstitions would have any correlation with these variables.

\subsection{Research Problem}

"Is locus of control is responsible for superstitious behaviour?"

\section{Objectives}

1) To study the relation between locus of control and superstitious behaviour among Rural Female.

2) To study the relation between locus of control and superstitious behaviour among Rural Male.

3) To study the relation between locus of control and superstitious behaviour among Urban Female.

4) To study the relation between locus of control and superstitious behaviour among Urban Male.

Sagone E. \& Carole M. (2014) reported that late adolescents were more internally LoC-believers than middle ones, while middle adolescents were more externally LoC-believers than late ones. Middle adolescents were more superstitious and greatly believed in good luck than late ones. The more the adolescents were internally LoC-believers, the less they believed in superstition; on the contrary, the more the adolescents were externally LoC-believers, the more they've put their faith in superstition and good luck. 
Mundada, N.D. (2013) analyzed the relationship between superstition and locus of control of 200 college students. Majority of the students have non superstition score in superstition scale. Externally controlled \& students from rural area show high level of superstition rather than internally controlled \& students from urban area. Female students show high level superstition than male students.

Ajzen, I. (2002) found that there is no necessary correspondence between self-efficacy and internal control factors, or between controllability and external control factors. Self-efficacy and controllability can reflect internal as well as external factors and the extent to which they reflect one or the other is an empirical question.

\section{Variables}

\subsection{Independent Variable}

\subsubsection{Locus of Control}

Locus of control is a term introduced by psychologist Julian B. Rotter that represents social learning theory's concept of internal versus external control of reinforcement (Kormanik \& Rocco, 2009). Locus of control refers to a predisposition in the perception of what causes reinforcement (Kormanik \& Rocco, 2009). Essentially, it is the degree to which individuals feel that they have control over reinforcements or outcomes of behaviours (Rotter, 1990). One would have internal locus of control if he or she feels as through consequences of his or her actions are contingent or personal behaviours or characteristics (Rotter, 1990). On the other hand, an individual with an external locus of control would expect that the outcome or reinforcement is a function of luck, fate or chance and that is consequence is generally unpredictable. (Rotter, 1990)

\subsection{Dependent Variable}

Superstitious behaviour is the dependent variable in this research. A stricter definition of the superstition (which, following Hood 2010, we henceforth refer to as a 'supernatural superstition') is one where there are no rational grounds to believe in a relationship between action and outcome, so that the agents prior belief is that the relationship is unlikely.

\section{Hypothesis}

Hypothesis of the research are:-

1) There is no significant relationship between locus of control and superstitious behaviour among rural female.

2) There is no significant relationship between locus of control and superstitious behaviour among rural male.

3) There is no significant relationship between locus of control and superstitious behaviour among urban female.

4) There is no significant relationship between locus of control and superstitious behaviour among urban male. 


\section{Materials and Methods}

\subsection{Sample and Sampling}

Sample is divided into four categories: - Rural Female, Urban Female, Rural Male and Urban Male.

Total 300 people has been included in the sample from UP.

"Quota sampling" has been used in this research.

Uttar Pradesh is the area chosen for sampling. Age limit of sample is 20 years to 40 years.

"Ex-post facto" research design has been used for this research.

\subsection{Tools}

- To assess the Locus of control in subjects "Rotter's Locus of control scale" of Dr. Kumar Anand \& Srivastav, S.N. (1985), Dept. of psychology, Kashi Vidyapith University, Varanasi is used. Reliability of the scale through split-half method is 0.78 and through testretest method is 0.73 . Rotter (1966) reported good discriminant validity for the scale indicated low correlation with such variables as intelligence, social desirability and political affiliation.

- To assess superstitious behaviour, scale has been developed by researcher. Reliability coefficient of scale has been found by test-retest method is 0.9. The Scale has shown content validity on the basis of experts rating, which were considered satisfactory.

\subsection{Statistical Method Used}

Chi-square has been used as statistical method to calculate the result.

\section{Result}

Hypothesis 1- There is no significant relationship between locus of control and superstitious behaviour among rural female.

Table 1: Percentage Table

\begin{tabular}{|l|l|l|l|}
\cline { 1 - 1 } Superstitious behaviour & \multirow{2}{*}{ Above Average } & Average & \multirow{2}{*}{ Below Average } \\
\cline { 1 - 1 } Locus of control & 54 & 41 & 5 \\
\hline Above Average & 31 & 52 & 17 \\
\hline Below Average & 17 & 50 & 33 \\
\hline
\end{tabular}


Table 2: Contingency Table

\begin{tabular}{|l|l|l|l|l|}
\cline { 1 - 4 } Superstitious Behaviour & & & & \\
\cline { 1 - 4 } Locus of control & Above Average & Average & Below Average & Total \\
\hline Above Average & 12 & 9 & 1 & \\
& $(7.3)$ & $(10.56)$ & $(4.1)$ & 22 \\
\hline Average & 9 & 15 & 5 & \\
& $(9.6)$ & $(13.92)$ & $(5.41)$ & 29 \\
\hline Below Average & 4 & 12 & 8 & \\
& $(8)$ & $(11.52)$ & $(4.48)$ & 24 \\
\hline Total & 25 & 36 & 14 & 75 \\
\hline
\end{tabular}

After calculation the value $\mathrm{X}^{2}=10.5415$, on $\mathrm{df}=4$. $\mathrm{P}$ lies between 0.05 and 0.01 . It has been clear from above table that relation between Locus of Control and Superstitious Behavior is significant. Hence, hypothesis is not accepted. Result indicates external locus of control leads to high superstitious behaviour among Rural Female.

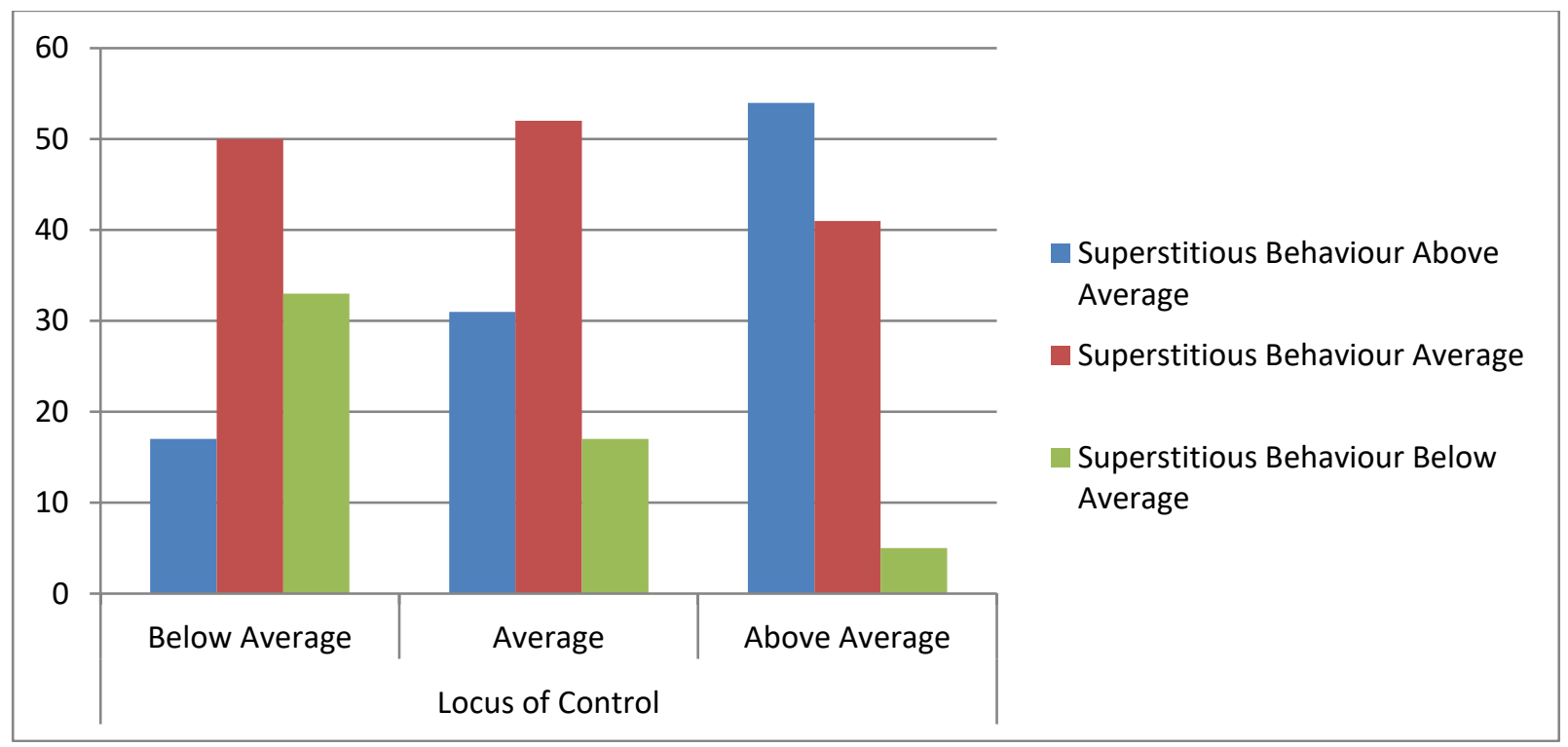

Graph 1: Percentage shows relationship between superstitious behaviour and Locus of control among rural female

Hypothesis 2- There is no significant relationship between locus of control and superstitious behaviour among rural male.

Table 3: Percentage Table

\begin{tabular}{|l|l|l|l|}
\cline { 1 - 3 } Superstitious Behaviour & Above Average & Average & Below Average \\
\cline { 1 - 4 } Locus of control & & & \\
\hline Above Average & 100 & 0 & 0 \\
\hline Average & 10 & 57 & 33 \\
\hline Below Average & 0 & 74 & 26 \\
\hline
\end{tabular}


Table 4: Contingency Table

\begin{tabular}{|l|l|l|l|l|}
\hline Superstitious Behaviour & \multirow{2}{*}{ Above Average } & Average & Below Average & Total \\
\hline Above Average & 9 & 0 & 0 & \\
\hline & $(1.56)$ & $(5.04)$ & $(2.4)$ & 9 \\
\hline Average & 4 & 22 & 13 & \\
\hline & $(6.76)$ & $(21.84)$ & $(10.4)$ & 39 \\
\hline Below Average & 0 & 20 & 7 & \\
\hline Total & $(4.68)$ & $(15.12)$ & $(7.2)$ & 27 \\
\hline
\end{tabular}

After calculation the value $\mathrm{X}^{2}=50.956$, on $\mathrm{df}=4$. $\mathrm{P}$ lies below 0.01. It has been clear from above table that relation between Locus of Control and Superstitious Behavior is significant. Hence, hypothesis is not accepted. Result indicates that external locus of control leads to high superstitious behaviour among rural male.

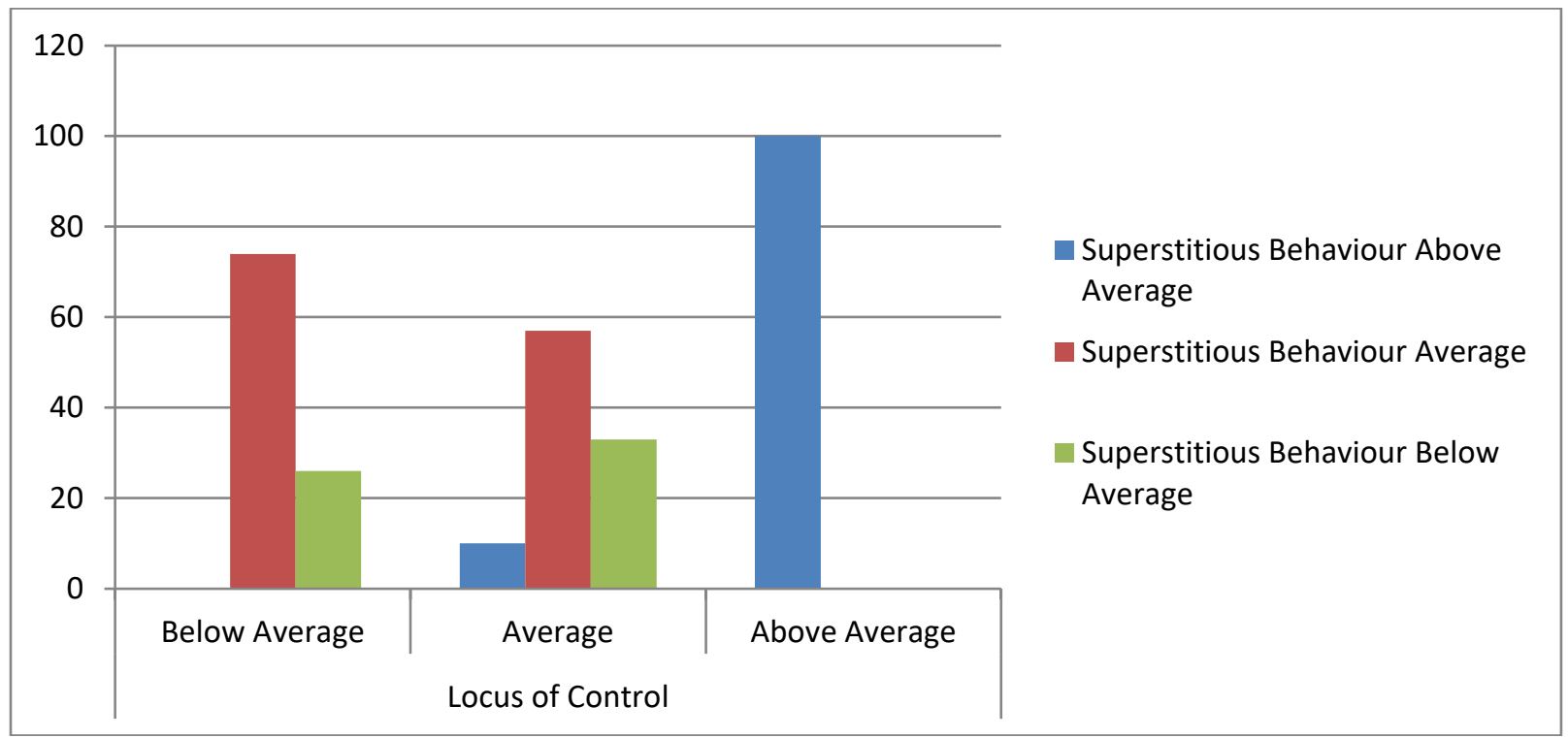

Graph 2: Percentage shows relationship between superstitious behaviour and Locus of control among rural male

Hypothesis 3- There is no significant relationship between locus of control and superstitious behaviour among urban female.

Table 5: Percentage Table

\begin{tabular}{|l|l|l|l|}
\hline Superstitious Behaviour & Above Average & Average & Below Average \\
\hline Locus of control & 100 & 0 & 0 \\
\hline Above Average & 9 & 49 & 42 \\
\hline Average & 2 & 49 & 49 \\
\hline Below Average & \multicolumn{2}{|l|}{} \\
\hline
\end{tabular}


Table 6: Contingency Table

\begin{tabular}{|l|l|l|l|l|}
\cline { 1 - 4 } Superstitious Behaviour & & & & \\
\cline { 1 - 4 } Locus of control & Above Average & Average & Below Average & Total \\
\hline \multirow{2}{*}{ Above Average } & 3 & 0 & 0 & \\
\cline { 1 - 4 } Average & $(0.28)$ & $(1.4)$ & $(1.32)$ & 3 \\
\hline \multirow{2}{*}{ Below Average } & 3 & 16 & 14 & \\
\hline Total & $(3.08)$ & $(15.4)$ & $(14.52)$ & 33 \\
\hline
\end{tabular}

After calculation the value $X^{2}=31.285$, on $\mathrm{df}=4$. P lies below 0.01 . It has been clear from above table that relation between Locus of Control and Superstitious Behavior is significant. Hence, hypothesis is not accepted. Result indicates that external locus of control leads to high superstitious behaviour among urban female.

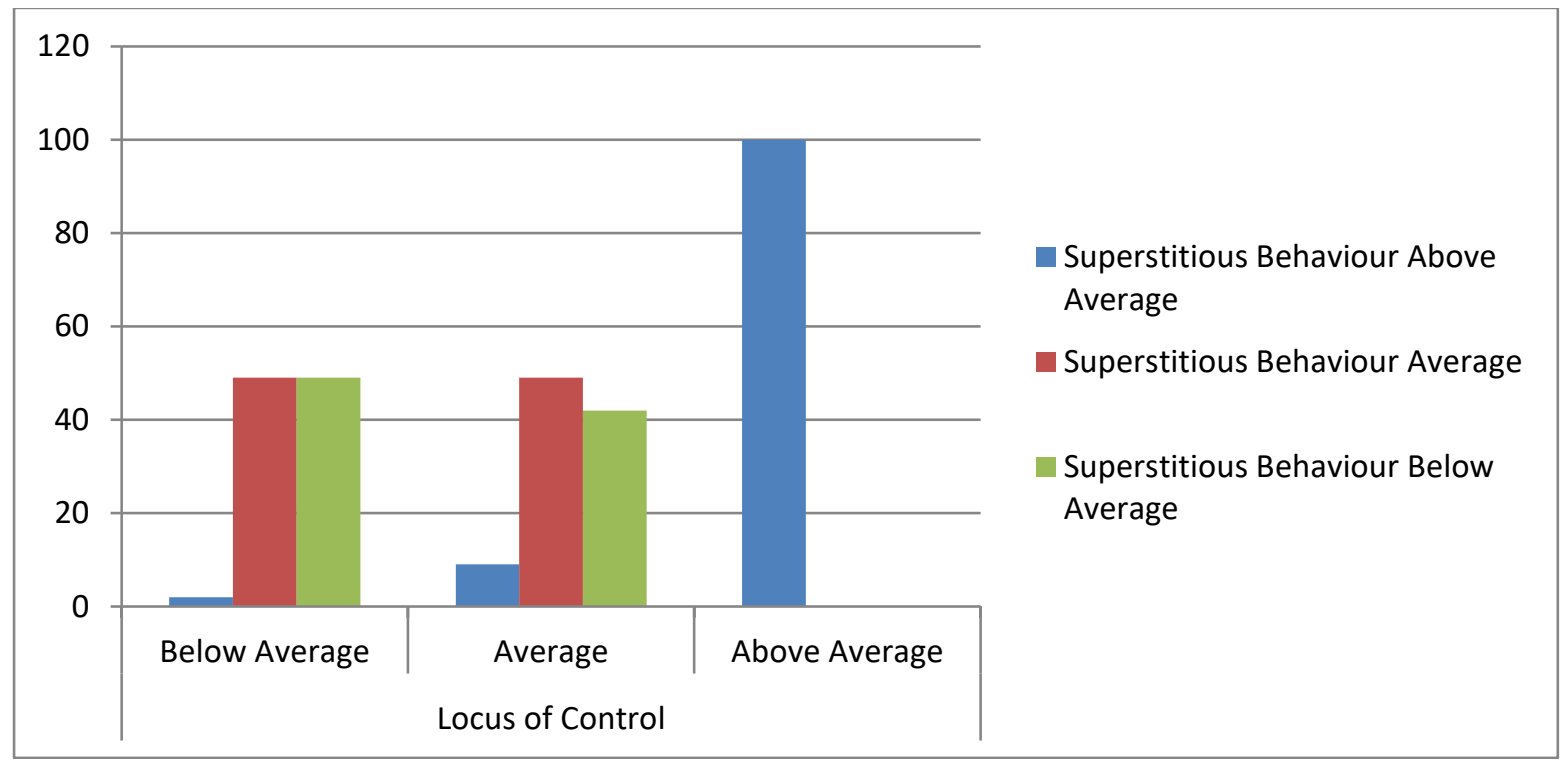

Graph 3: Percentage shows relationship between superstitious behaviour and Locus of control among urban female

Hypothesis 4- There is no significant relationship between locus of control and superstitious behaviour among urban male.

Table 7: Percentage Table

\begin{tabular}{|l|l|l|l|}
\hline Superstitious behaviour & \multirow{2}{*}{ Above Average } & Average & \multirow{2}{*}{ Below Average } \\
\cline { 1 - 4 } Locus of control & 100 & 0 & 0 \\
\hline Above Average & 3 & 73 & 24 \\
\hline Bverage & 0 & 56 & 44 \\
\hline
\end{tabular}


Table 8: Contingency Table

\begin{tabular}{|l|l|l|l|l|}
\hline Superstitious Behaviour & \multirow{2}{*}{ Above Average } & Average & Below Average & Total \\
\hline Above Average & 6 & 0 & 0 & \\
\hline & $(0.56)$ & $(3.6)$ & $(1.84)$ & 6 \\
\hline Average & 1 & 27 & 9 & \\
\hline & $(3.45)$ & $(22.2)$ & $(11.35)$ & 37 \\
\hline Below Average & 0 & 18 & 14 & \\
\hline Total & $(2.99)$ & $(19.2)$ & $(9.81)$ & 32 \\
\hline
\end{tabular}

After calculation the value $\mathrm{X}^{2}=66.415$, on $\mathrm{df}=4$. P lies below 0.01 . It has been clear from above table that relation between Locus of Control and Superstitious Behavior is significant. Hence, hypothesis is not accepted. Result indicates that external locus of control leads to high superstitious behaviour among urban male.

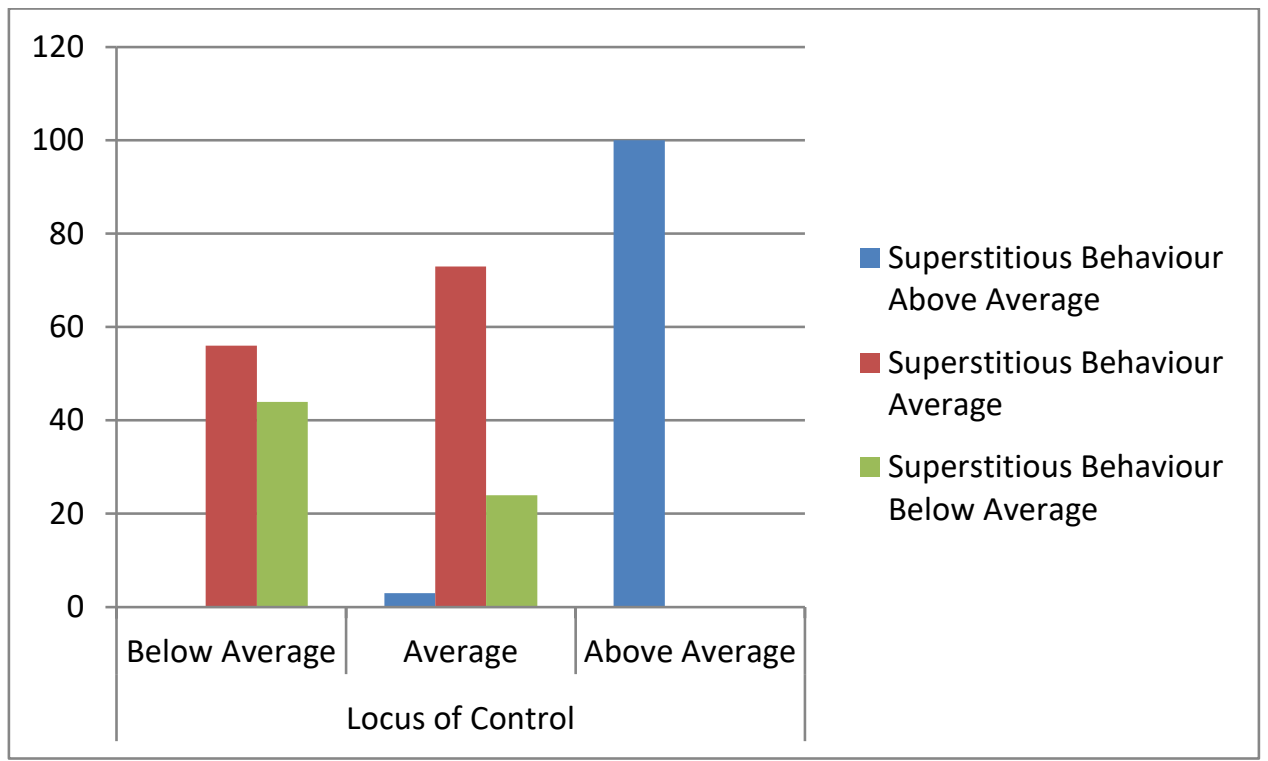

Graph 4:- Percentage shows relationship between superstitious behaviour and Locus of control among urban male

\section{Discussion}

Result supported by some previous researches conducted by Sagone, E. \& Carole, M. (2014) reported that more the adolescents were internally LoC-believers, the less they believed in superstition; on the contrary, the more the adolescents were externally -LoC believers, the more they've put their faith in superstition and good luck. Mudada, N.D. (2013) analysed the relationship between superstition and locus of control of 200 college students. Externally controlled \& students from rural area show high level of superstition rather than internally controlled \& students from urban area. Female students show high level superstition than male students. Farooq, A., Kayani, A.K. (2012) analysed that sizable proportion of the people believe in various superstitions, meaningful dreams and supernatural aspects such as black magic, taweez 
and ghosts. Schippers, M.C., Paul A.M.V.L. (2006) revealed that players with an external locus of control exhibited greater levels of ritual commitment than did players with an internal locus of control. Stanke, A., Taylor,M. (2004) examined two possible correlates of superstition: religiosity and locus of control. ANOVA suggests that levels of religiosity do not have a significant relationship with levels of superstitious beliefs. Analyses do reveal a positive relationship between external or chance loci of control and superstitious belief. The correlations of external and chance loci of control with higher superstitious beliefs may implicate a tendency for such individuals to view life as uncontrollable, hard to deal with, or affect their self-efficacy. Wiseman,R. (2003) found that women are more superstitious than men, and young people more than old. Torgler, $\mathbf{B}$. (2003) found that socio-economic variables matter. Furthermore, there is the tendency that people without a religious denomination have the lowest belief in superstition. Finally, the results indicate that there is a strong variety in superstition among countries.

\section{Conclusion}

The outcome of this research is, external locus of control is only responsible for superstitious behavior in people. Concluded that people who believe that situation of life is controlled by external factors, believe in superstitions.

\section{References}

[1] Ajzen, I. (2002). Perceived behavioural control, self-efficacy, locus of control and the theory of planned behavior. Journal of Applied Social Psychology. 32(4).665-683. Retrieved from: http://www.onlinelibrary.wiley.com/doi/10.1111/j.1559-1816.2002.tb00236.x/abstract

[2] Kormanik, M.B., Rocco, T.S.(2009). Internal versus external control of reinforcement: A Review of the Locus of control construct. Human Resource Development Review. 8(4). 463-483. Doi: $10.1177 / 1534484309342080$

[3] Kumar,A., Srivastava,S.N. (1985). Rotter's Locus of Control Scale, I-E Scale. Hindi Adaptation [Measurement Instrument]. Varanasi, UP: Kumar Publications

[4] Lefcourt, H.M.(1966). Internal versus external control of reinforcement: A review. Psychological Bulletin, 65, 4, 206-20.

[5] Lefcourt, H.M.(1976). Locus of control: Current Trends in Theory and Research. NJ: Lawrence Erlbaum Associates

[6] Mamlin, N., Harris, K.R., Case, L.P. (2001). A methodological analysis of research on Locus of Control and Learning Disabilities: Rethinking a common assumption. Journal of Special Education, Winter

[7] Mundada, N.D. (2013). Locus of Control and Superstitions. International Journal of Humanities and Social Science Invention.2 (6). Pp.01-04. Retrieved from:

http://s3.amazonaws.com/academia.edu.documents

[8] Rotter, J.B. (1954). Social Learning and Clinical Psychology.NY: Prentice-Hall

[9] Rotter, J.B. (1966). Generalized expectancies of Internal versus External control of reinforcements. Psychological Monographs. 80, 609

[10] Rotter,J.B.(1990). Internal versus External control of Reinforcement: A case history of a variable, American Psychologist, April 1990, 490-493

[11] Saadat, M., Ghasemzadeh,A., Karami,S., Saleimani,M.. (2012). Relationships between self-esteem and locus of control in Iranian University students. Procedia-Social and Behavioural Sciences. 31. P. 530-535. Retrieved from: https://doi.org/10.1016/j.sbspro.2011.12.099 
[12] Sagone, E., Carole, M.E. (2014). Locus of control and beliefs about superstition and luck in adolescents: what's their Relationship?. Procedia- social and behavioural sciences. 140.318-323. Retrieved from: https://doi.org/10.1016/j.sbspro.2014.04.427

[13] Stanke, A. (2004). Religiosity, Locus of control and superstitious belief. UW-L. Journal of undergraduate research VII. Retrieved from: https://www.uwlax.edu/urc/JUR-online/PDF/2004/stanke.pdf

[14] Smith,V.L.(2003). Analyses of locus of control and educational level utilizing the internal control index. Theses.Dissertations and Capstones. Paper 881. Retrieved from: http://mds.marshall.edu/etd/881/

*Corresponding author.

E-mail address: Manasvi.shri@ gmail.com 